\title{
'Revolutionary' telescope gets green light
}

David Adam, London

Astronomers have finally got the official go-ahead to build the world's most powerful radio telescope, in the Chilean Andes.

The \$650-million Atacama Large Millimeter Array (ALMA) is expected to help researchers explore processes such as the formation of galaxies, stars and planets, the intricacies of which are obscured from the most powerful optical telescopes by dust clouds.

But millimetre-range wavelength radiation will pass through these clouds and be detected by ALMA. The telescope will use 64 portable dishes spread over an area $14 \mathrm{~km}$ across to observe it with a spatial resolution up to 50 times higher than the most powerful current instruments, such as the IRAM array at Plateau de Bure in the French Alps.

"It's going to be revolutionary," predicts Peter Shaver, an astronomer with the European Southern Observatory (ESO), based in Garching, Germany. "Even our largest optical telescopes cannot see through the dust, so ALMA will allow direct observations of planet, star and galaxy formation for the first time."

ALMA will analyse higher radio frequencies than the existing Very Large Array, a radio telescope array in New Mexico, which observes cosmic events such as black holes. It will also pick up signals in a different part of the electromagnetic spectrum from the planned James Webb Space Telescope (JWST), which will observe infrared radiation (see page 3 ).

And unlike the JWST, ALMA's completion

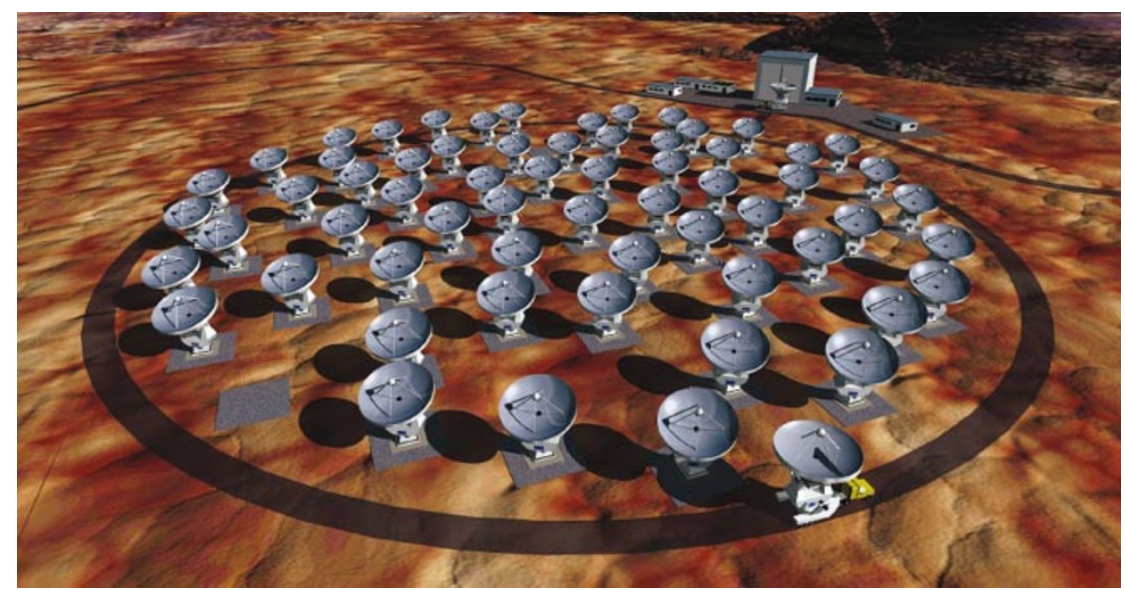

A veritable array: ALMA's 64 antennas will allow the first direct observations of planet formation.

is fully assured: at a meeting in Washington DC on 25 February, representatives of the ESO and the US National Science Foundation signed the official agreement to build it. Both had already said that they would reach the agreement, "but it's still a relief to have it signed and sealed", says Richard Kurz, who is European project manager for ALMA and is also based at the ESO's Garching headquarters. Construction will now begin later this year, with the first scientific results due by the end of 2007 .

One signature missing is that of Japan. Although Japanese astronomers had hoped to participate in the project from the outset (see Nature 401, 627-628; 1999), their government has not yet committed any funding. If this situation changes, the current 'baseline' plans for ALMA could be upgraded, Kurz says. "Extra Japanese funding would allow us to add on some additional features," he explains.

ALMA will also help Chile to continue to develop local astronomy expertise: its scientists will receive $10 \%$ of the available viewing time on the telescope, and the project partners say that they will pay student fellowships to allow young Chilean researchers to work with the new facility.

Ultimately, the team hopes that the ALMA array will be able to monitor radiation with wavelengths of $0.33-10 \mathrm{~mm}$, divided into 10 convenient bands. For now, instruments operating in just four of these bands are planned, but Kurz says that others can be added later.

\section{Climate studies hold key to future of desalination plant}

\section{Rex Dalton, San Diego}

Palaeontologists and hydrologists are being called in to help the US government decide what to do with a disused, $\$ 400$-million desalination plant on the banks of the Colorado River.

The researchers will study tree rings and clam shells, among other things, in a bid to establish long-term historical climate patterns in the river basin. These will help the US Bureau of Reclamation to determine whether it is worth reopening the Yuma Desalting Plant, which was designed to remove salt from the river before it reaches Mexico.

The plant was completed in Arizona in 1989, after salty water from the Colorado River had upset agricultural and natural ecosystems in Mexico. The salty water had entered the river from irrigation run-off from agricultural fields, particularly in western Arizona. Other steps taken to address the problem included building a canal to divert agricultural run-off to a marsh near the Gulf of California.

The desalination plant was operated for a test period of about six months in 1992. But in January 1993, heavy rains diluted the river, making desalination operations unnecessary. The plant was subsequently criticized in media reports as a waste of taxpayers' money, and environmental groups complained about the potential impact of brine extracted by the plant that was sent to the Mexican marshland.

But a four-year drought in Arizona has led officials to try to find new ways of securing more usable water, while



meeting the requirements of the complex laws and treaties covering the river. A treaty signed in 1944 requires the United States 


\section{Agency 'ignoring its advisers' over Bt maize}

Jonathan Knight, San Francisco

A strain of maize that is genetically modified to fight rootworm - a major crop pest - has won approval from the US Environmental Protection Agency. But scientists who were consulted before the 25 February decision say that the agency ignored their advice and is doing too little to ensure that insects don't develop resistance to the insecticide produced by the plant.

Last October, a scientific review board recommended that the strain should only be grown if farmers plant an equal area of nontransgenic maize next to it. Such a stipulation would have undermined the commercial viability of the strain, however, and the EPA has rejected it, saying that a $20 \%$ "refuge" of non-transgenic maize will suffice.

The decision has drawn immediate fire from members of the review board.

"They are putting the issue of sustainability on the back burner," argues Fred Gould, an entomologist at North Carolina State University in Raleigh.

The new Bt maize - developed by Monsanto of St Louis, Missouri, to express an insect toxin gene from the bacterium Bacillus thuringiensis - differs from existing varieties in several ways. The $B t$ maize that is already widely planted in the United States targets the European corn borer, a moth whose larvae eat stalks and leaves, but is useless against the corn rootworm, a beetle that costs farmers US $\$ 1$ billion a year in pesticide treatments.

The various strains of $B t$ bacteria collectively produce some 40 classes of insect toxin,

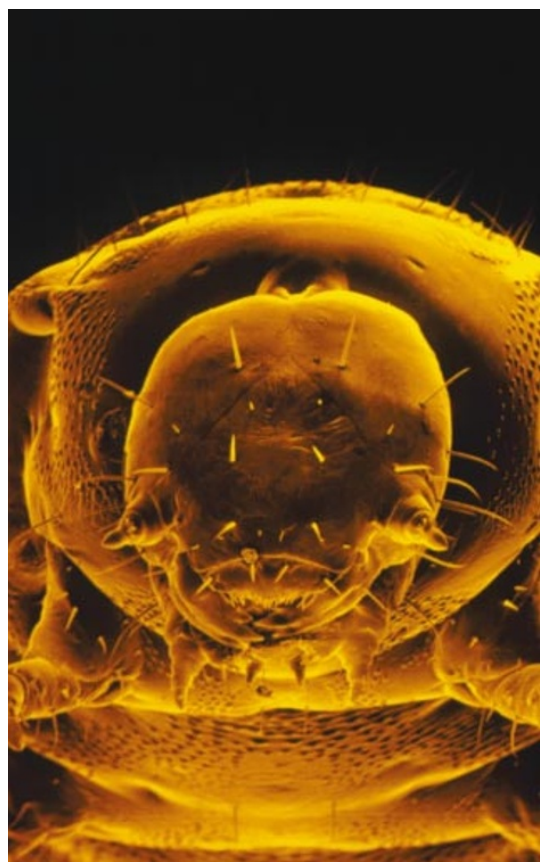

Rootworm: could low-dose $B t$ create resistance?

and the new variety of maize incorporates one that attacks only the corn rootworm and its close relatives. But it also produces much less toxin than existing $B t$ crops increasing the prospect that insect populations will have time to develop resistance to the toxin. To mitigate this risk, refuges of non- $B t$ varieties are planted so that susceptible insects can multiply. These then mate with resistant insects and dilute out

the resistance genes in the next generation.

But this strategy only works if the transgenic plants produce enough toxin to ensure that only a very small number of insects (which might spawn resistant offspring) survive, say Gould and other critics of the EPA decision. If the crop produces too little $B t$ toxin, the survivors will include a large number of partially resistant insects who are likely to find each other and enrich the gene pool for resistance, they say.

Whereas established $B t$ maize varieties produce high doses of toxin, the new variety kills only about half the rootworm larvae, according to data provided by Monsanto to the EPA. This is enough to help farmers, Monsanto claims, because it is just as effective as pesticide treatments and has the advantages of saving time and doing less damage to the environment.

But with such a low mortality rate, resistance is certain to arise, the strain's critics say - the only question is when. Farmers can delay resistance by planting larger refuges. So Gould and ten other members of a scientific review board that looked at Monsanto's application urged the EPA to require a refuge size of at least $50 \%$ of the total area planted with corn.

In its ruling, however, the EPA sided with three dissenting review-board members, and sanctioned the $20 \%$ refuge size that Monsanto had requested. EPA spokesman David Deegan says that the agency's own calculations suggest that even if the new variety were planted all over the United States, it would take between 7 and 16 years for resistance to become a problem. Monsanto expects its anti-rootworm corn to cover no more than 5 million acres - 6\% of US cornfields - by 2005.

"The registration is just for three years, and I don't think resistance is going to emerge in three years," argues Richard Hellmich, one of the board's dissenters and an entomologist with the Agricultural Research Service, the research arm of the US Department of Agriculture, in Ames, Iowa. Hellmich's group is one of several that will be monitoring rootworm in $B t$ fields for signs of resistance during this time. Refuge requirements can be changed later if necessary, he adds.

But by then it may be too late, warns Margaret Mellon, who directs the Food and Environment programme at the Union of Concerned Scientists, an advocacy group based in Cambridge, Massachusetts. It is hard to get farmers to plant less of something if they like it, she argues, and once a resistant population of insects arises, it can be very hard to eliminate.

"We need to protect $B t$ as a valuable resource and not use it up," she says. 